University of Nebraska - Lincoln

DigitalCommons@University of Nebraska - Lincoln

Faculty Papers and Publications in Animal

Science

Animal Science Department

August 2005

\title{
Authors' response to the Letter to the Editor by Schinckel
}

R. K. Johnson

University of Nebraska-Lincoln, rjohnson5@unl.edu

E. P. Berg

University of Missouri, Columbia

R. Goodwin

National Pork Board, Clive, IA

J. W. Mabry

lowa State University

R. K. Miller

Texas A\&M University, College Station

See next page for additional authors

Follow this and additional works at: https://digitalcommons.unl.edu/animalscifacpub

Part of the Animal Sciences Commons

Johnson, R. K.; Berg, E. P.; Goodwin, R. ; Mabry, J. W.; Miller, R. K.; Robison, O. W.; Seller, H.; and Tokach, M. D., "Authors' response to the Letter to the Editor by Schinckel" (2005). Faculty Papers and Publications in Animal Science. 67.

https://digitalcommons.unl.edu/animalscifacpub/67

This Article is brought to you for free and open access by the Animal Science Department at DigitalCommons@University of Nebraska - Lincoln. It has been accepted for inclusion in Faculty Papers and Publications in Animal Science by an authorized administrator of DigitalCommons@University of Nebraska - Lincoln. 


\section{Authors}

R. K. Johnson, E. P. Berg, R. Goodwin, J. W. Mabry, R. K. Miller, O. W. Robison, H. Seller, and M. D. Tokach 


\section{Authors' response to the Letter to the Editor by Schinckel}

In this letter, we provide responses to the issues raised by A. P. Schinckel in his Letter to the Editor regarding the manuscript by Johnson et al. (2004), "Evaluation of procedures to predict fat-free lean in swine carcasses," J. Anim. Sci. 82:2428-2441. General responses to Schinckel's letter are made first, followed by specific responses to each issue raised.

Schinckel cited several references to support his positions. The Boland et al. (1995) paper, addressing effects of operator error on variation in optical probe measurements, is work initiated by E. P. Berg, a coauthor of our paper, as a side project to his Ph.D. dissertation research. We are well aware of this source of variation. Except for Neter et al. (1996), a statistics text, and StPierre (2003), who addressed bias in predicting $\mathrm{N}$ flow in the duodenum of dairy cows, the papers cited by Schinckel are interpreted strictly from his perspective. Three of the papers referenced in Schinckel's letter were cited in our paper (Gu et al., 1992; Wagner et al., 1999; Schinckel et al., 2001), indicating our knowledge of this work. The other paper Schinckel references is a Purdue Swine Day Report (Schinckel et al., 2000) that we were not aware of, but we do not believe that it warranted citation in our paper.

Our paper accurately reported what was done. Different readers will interpret results differently. Schinckel's letter and citations suggest that he believes that his methods and interpretations are the only correct ones. We believe differently and, in the following numbered paragraphs, provide a response to each of the issues raised in the same paragraph order as presented in Schinckel's Letter to the Editor.

1. Paragraph 1. As pointed out by Schinckel, regressions of residuals on the observed y values do not estimate bias. The authors were guided by Draper and Smith (1981) in which the principal ways of plotting residuals are recommended as "overall, in time sequence, against the fitted values, $\hat{y}$, against the independent variables, $\mathrm{x}_{\mathrm{i}}$, and in any way that is sensible for the particular problem under consideration." The last of these leaves considerable leeway. Residuals were analyzed by regressing them on the $\mathrm{x}_{\mathrm{i}}$ values, by calculating mean residuals for fixed-effect classes and then comparing these means, and by regression on $\mathrm{y}$. Because $\mathrm{e}=$ $\mathrm{y}-\hat{Y}$, it seemed that if regression on $\hat{Y}$ is sensible, it is also sensible to regress them on y; however, the expected value of this regression is $1-r^{2}$, a meaningful statistic, but not bias. We clearly

August 8, 2005. stated what was done; the other investigations of residuals are appropriate, are interpreted correctly, and show that the prediction equations tend to overestimate lean in fat pigs and underestimate it in lean pigs - the same conclusion drawn from regressions of residuals on y. Readers of the paper are advised to interpret the regressions of residuals on the observed y values as estimates of $1-r^{2}$.

2. Paragraph 2. We do not follow the logic of Schinckel's issue described in this paragraph. We did exactly as Schinckel recommends-the magnitude of bias was compared for each population, sex, and dietary treatment. We do not believe that calculating the percentage of the variance caused by each of these sources adds to understanding of bias or improves application of the equations. Schinckel's example about Berkshire pigs suggests that we should have a separate equation for each breedsex-diet combination. That, of course, would be the optimum application. However, this is not how the industry applies prediction because this information is seldom known for pigs delivered to slaughter plants. The goal was to derive prediction equations for use across populations and management regimens as is done in practice.

3. Paragraph 3. Schinckel's criticism of experimental technique in this paragraph is unfounded and contradicts his own work. The carcass separation procedures are clearly defined in the manuscript and are further supported with Institutional Meat Purchase Specification numbers for each cut. The Institutional Meat Purchase Specification numbers relate to actual cuts used by the industry and are a standard method of cutting. These cutting methods are closely aligned with the procedures defined by Wagner et al. (1999). Wagner et al. (1999) removed external subcutaneous and seam fat and defined the outcome as dissectable fat, whereas we defined the outcome as knife-separable fat. Both papers sufficiently describe procedures.

Much of the research on pork carcass cutting procedures has used either knife-separable or knife-dissectable fat, which are methods accepted broadly by meat scientists. Before our project was initiated, a committee of meat scientists approved the procedures used. In addition, meat science post-doctoral research associates or graduate students trained in the procedures constantly supervised carcass dissections. We point out that within the scientific literature, cutting procedures and endpoints to evaluate carcass lean vary. The use 
of fat-free lean as a compositional index is a measurement that helps to remove the variation in cutting methods used across projects. We stated clearly that the fat components from the cuts were combined and analyzed for lipid content. This lipid content was used to adjust the data as defined in the literature to obtain fat-free lean. The Folch method of lipid extraction was used in our work. This lipid extraction method is well-documented in the meat science literature and is used as an indicator of lipid content in meat, as it accounts for the phospholipid and triacylglycerol components of lipid.

Although not the same, estimates of lipid-free and fat-free lean are highly correlated, as discussed in our paper. Both variables were analyzed, but only results for fat-free lean were included in the paper. The same effects were significant for both variables, and prediction equations had similar relative accuracies. Furthermore, in the data we analyzed, the correlation between weight of lipid-free and fat-free lean calculated within fixedeffect classes was 0.96 before correction for weight and 0.94 after correction for weight. In our paper, we acknowledged that the variables are highly correlated and cited Schinckel's work as supporting evidence. Schinckel et al. (2003) reported that the correlations between weights and percentages of these two components were 0.97 and 0.96 , respectively. Schinckel et al. (2003) also reported only minor differences in the ranking of $R^{2}$ and relative SD statistics for prediction of fat-free and lipid-free lean with the same independent variables. Therefore, in our discussion, to avoid the redundancy of having to define explicitly the method used in work cited by others, prediction by both procedures was referred to as fat-free lean.

4. Paragraphs 4 and 5. Here Schinckel summarizes his own work, but other than acknowledging that fact, we do not know what else to make of it. Because prediction equations are used across a wide weight range, we chose to develop them in that way rather than within weight range classes. The quadratic carcass weight component was significant only for the Automated Ultrasonic System equation. It is possible that the cross-product terms and other quadratic terms that were significant in some equations are related to populations and sexes. If so, this is a desirable outcome, as these terms thereby account for different relationships in different populations. There was considerable overlap of weights across all populations. Therefore, Schinckel's suggestion that cross-product and quadratic terms entered some equations because different populations were evaluated at different weights is speculative and highly unlikely.
5. Paragraph 6. The Ultrasonic Fat-o-Meater (UFOM) equation may not look right, but it is the best-fitting one for the data, and the coefficients are accurate. (Analyses were repeated to confirm the accuracy of the reported equation.) The UFOM equation was estimated with the fewest data and also had the greatest variation. A check of the data did not reveal odd outliers that might have affected results.

6. Paragraph 7. Here, Schinckel contends that significant variance caused by groups (slaughter day) and variation in the magnitude of this component of variance for different equations are indicators of bias. The component of variance for weight of fat-free lean ranged from $0.40 \mathrm{~kg}^{2}$ for UFOM $(3.1 \%$ of the total variation) to $2.21 \mathrm{~kg}^{2}$ for the Automated Ultrasonic System (18.5\% of the total variance). For the remaining procedures, this variance component was quite consistent, accounting for 8.5 to $15.6 \%$ of the total variance. Contrary to Schinckel's statement, these variances were not calculated on the same set of pigs nor were the same slaughter days represented for all equations. The number of carcasses evaluated ranged from 126 (UFOM) to 1,024 (carcass last-rib backfat). Several things likely contributed to this source of variation, and identifying them is not possible. Slaughter day was included in models simply to account for that source of variation. Little is made of this point in the paper except to indicate possible causes of this source of variation.

\section{Literature Cited}

Draper, N. R., and H. Smith. 1981. Applied Regression Analysis. 2nd ed. Wiley, New York, NY.

Schinckel, A. P., C. T. Herr, B. T. Richert, J. C. Forrest, and M. E. Einstein. 2003. Ractopamine treatment biases in the prediction of pork carcass composition. J. Anim. Sci. 81:16-28.

\footnotetext{
R. K. Johnson, ${ }^{1}$ E. P. Berg, ${ }^{2}$ R. Goodwin, ${ }^{3}$ J. W. Mabry, ${ }^{4}$ R. K. Miller, ${ }^{5}$ O. W. Robison, ${ }^{6}$ H. Sellers, ${ }^{7}$ and M. D. Tokach ${ }^{8}$

${ }^{1}$ Animal Science Dept., Univ. of Nebraska, Lincoln 68581-0908;

Corresponding author: Rjohnson5@unl.edu ${ }^{2}$ Animal Science, Univ. of Missouri, Columbia 65211-5300;

${ }^{3}$ National Pork Board, Clive, IA 50325;

${ }^{4}$ Dep. of Animal Science, Iowa State Univ., Ames 50011;

${ }^{5}$ Dep. of Animal Science, Texas A\&M Univ., College Station 77843-2471;

${ }^{6}$ Dep. of Animal Science, North Carolina State Univ., Raleigh 27695;

${ }^{7}$ Des Moines, IA 50310-3009; and

${ }^{8}$ Animal Sciences and Industry, Kansas State Univ., Manhattan 66502.
} 